\title{
Article \\ Genome-Wide Identification and Functional Investigation of 1-Aminocyclopropane-1-carboxylic Acid Oxidase (ACO) Genes in Cotton
}

\author{
Hengling Wei ${ }^{1,+}$, Yujun Xue ${ }^{1,+}$, Pengyun Chen ${ }^{1}$, Pengbo Hao ${ }^{1}$, Fei Wei ${ }^{1}$, Lu Sun ${ }^{2}$ and Yonglin Yang ${ }^{3, *}$ \\ 1 State Key Laboratory of Cotton Biology, Institute of Cotton Research of CAAS, Anyang 455000, China; \\ henglingwei@163.com (H.W.); Xyujun2021@163.com (Y.X.); arpengyun@163.com (P.C.); \\ hao_pengbo@163.com (P.H.); weifei888000@outlook.com (F.W.) \\ 2 Handan Academy of Agricultural Sciences, Handan 056001, China; sunlu1217.ok@163.com \\ 3 Shihezi Academy of Agricultural Sciences, Shihezi 832099, China \\ * Correspondence: 13095092255@163.com \\ + The authors contributed equally to this work.
}

check for updates

Citation: Wei, H.; Xue, Y.; Chen, P.; Hao, P.; Wei, F.; Sun, L.; Yang, Y. Genome-Wide Identification and Functional Investigation of

1-Aminocyclopropane-1-carboxylic Acid Oxidase (ACO) Genes in Cotton. Plants 2021, 10, 1699. https://doi.org/ $10.3390 /$ plants10081699

Academic Editors: Bhakti Prinsi and Luigi Lucini

Received: 30 June 2021

Accepted: 14 August 2021

Published: 18 August 2021

Publisher's Note: MDPI stays neutral with regard to jurisdictional claims in published maps and institutional affiliations.

Copyright: (c) 2021 by the authors. Licensee MDPI, Basel, Switzerland. This article is an open access article distributed under the terms and conditions of the Creative Commons Attribution (CC BY) license (https:/ / creativecommons.org/licenses/by/ $4.0 /)$.

\begin{abstract}
ACO is one of the rate-limiting enzymes in the biosynthesis of ethylene, and it plays a critical role in the regulation of plant growth and development. However, the function of $A C O$ genes in cotton is not well studied. In this study, a total of 332 GhACOs, 187 GaACOs, and 181 GrACOs were identified in G. hirsutum, G. arboretum, and G. raimondii, respectively. Gene duplication analysis showed that whole-genome duplication (WGD) and tandem duplication were the major forces driving the generation of cotton $A C O$ genes. In the promoters of GhACOs, there were cis-acting elements responding to stress, phytohormones, light, and circadian factors, indicating the possible involvement of GhACOs in these processes. Expression and co-expression analyses illustrated that most GhACOs were not only widely expressed in various tissues but also coexpressed with other genes in response to salt and drought stress. GhACO106_At overexpression in Arabidopsis promoted flowering and increased salt tolerance. These results provide a comprehensive overview of the $A C O$ genes of cotton and lay the foundation for subsequent functional studies of these genes.
\end{abstract}

Keywords: G. hirsutum; ACO gene; expression patterns; flowering; stress response

\section{Introduction}

Ethylene has a variety of physiological regulatory functions throughout the life of plants, including roles in flower formation, fruit maturation, and senescence [1-4]. ACO is the last enzyme in the ethylene synthesis pathway [1,3]. The first identified ACO gene was PTOM13, which was cloned from tomato fruit in 1985 and confirmed as an ethyleneforming enzyme in 1991 [5].

In tobacco, inhibiting the expression of an ACO-like gene leads to female sterility of transgenic plants and this functional defect can be recovered by treatment with ethylene [6]. In cucumber, $\mathrm{Cs} A C \mathrm{CO} 2$ was found to be the main gene required for the development of carpels [7]. In tomato, with the exception of LeACO2, all the other five ACO genes are expressed during different stages of fruit ripening, and $A C O$ transgenic tomato fruits are more resistant to storage and shrinkage than control fruits, showing that $A C O$ genes are related to fruit ripening in tomato [8-12]. In apple, peach, strawberry, and banana, the expression of $A C O$ genes also changes during fruit ripening, so it is hypothesized that the $A C O$ genes have a universal function related to fruit ripening [13-16]. In carnation, $A C O$ gene expression can be induced during flowering, pollination, and petal senescence $[17,18]$. In soybean, Zabala et al. hypothesized that the overexpression of an ACO gene precedes the development of minute hilum seed coat phenotype [19].

The ACO genes have also been reported to be involved in the responses to environmental stress and hormones [20,21]. In Arabidopsis, TaACO1 can be negatively regulated by 
salinity stress [22]. Additionally, flood tolerance develops following the overexpression of an ACO gene in Arabidopsis [23]. In sunflower, under salt stress, nitric oxide was found to regulate lateral root formation through the modulation of $A C O$ gene activity [24]. In cucumber and tomato, $A C O$ gene expression can be induced by wounding $[10,25]$. In potato, the mRNA level of ST-ACO3 increases following inoculation with F. eumartii [26]. In tomato and cauliflower, $A C O$ genes have been found to respond to $A B A$ and mechanical damage $[27,28]$. The expression of OsACO1 can also be induced by external mechanical damage, and IAA can significantly increase the expression of OsACO2 while completely inhibiting that of OsACO3 [29,30]. In Agrostis stolonifera, AsACO is strongly upregulated in response to ethephon (ETH), methyl jasmonate (MeJA), salicylic acid (SA), and cold temperature but is downregulated in response to drought and salt stresses [31].

Gossypium originated approximately 10 million years ago and then experienced rapid speciation and differentiation events [32]. To date, 52 cotton genera, including 45 diploid and 7 natural tetraploid genomes, have been discovered and named [33]. It has been theorized that allotetraploid upland cotton (AADD, $2 n=4 \times=52$ ) probably originated approximately 1-2 million years ago (MYA) via the natural hybridization of the diploid genomes of $G$. arboreum (AA, $2 n=2 \times=26$ ) and G. raimondii (DD, $2 n=2 \times=26$ ) [34]. As the main generator of natural fibers for the textile industry, the genus Gossypium is widely planted worldwide. The planting area of upland cotton (G. hirsutum) accounts for more than $95 \%$ of the global cotton planting area due to its excellent agricultural traits, such as high yield, superior fiber, and strong stress tolerance. In addition, the members of the Gossypium genus are used as model plants for studying plant cell elongation, cell wall and cellulose synthesis, and polyploid evolution.

As a multigene family with multiple functions, $A C O$ genes have been cloned from a variety of plants such as melon, carnation, and Arabidopsis [17,20,35-37]. However, the identification and functional characterization of $A C O$ genes in cotton is rarely reported. In this study, $A C O$ genes were identified from three cotton species, and their physicochemical properties, domain architectures, phylogenetic relationships, syntenic relationships, and spatiotemporal expression were analyzed. Furthermore, the function of an ACO gene, GhACO106_At, was investigated by performing an overexpression assay in Arabidopsis.

\section{Results}

\subsection{Identification and Sequence Analysis of ACO Genes in Cotton}

In total, 332 GhACOs, 187 GaACOs, and 181 GrACOs were identified from G. hirsutum $(G h), G$. arboretum $(G a)$, and $G$. raimondii $(G r)$, respectively. Basic information on these $A C O$ genes is listed in Supplementary Table S1. The lengths of the proteins encoded by these ACO genes ranged from 191 to 979 amino acids (aa); their molecular weights (MWs) ranged from 21,926.19 to 110,977.16; their pI values ranged from 4.64 to 9.72; and their grand average of hydropathicity (GRAVY) values ranged from -0.607 to $0.01(-0.021)$. These $A C O$ genes were divided into four subgroups based on phylogenetic analysis. The largest group (Group IV) contained 277 genes, the smallest group (Group I) contained only 63 genes, and Group II and Group III each contained 180 genes (Supplementary Figure S1). In total, 10 conserved motifs were detected in these cotton ACO proteins. Among these 10 motifs, motif 9 was the most conserved domain and was found in 698 cotton ACO proteins (Figure S2 and Table S2).

The upstream sequences of the GhACOs were retrieved, and cis-acting elements were predicted. The results showed that the promoters included elements that respond to stress, phytohormones, and light. The stress response elements included drought response (DRE core, DRE1, MBS, MYB recognition site, MYC, and as-1), water stress response (MYB and AT-rich element), heat stress response (STRE), metal response (AP-1 and O2-site), wounding and pathogen response (W box, box S, WRE3, and WUN-motif), and anoxic response (GCmotif) elements. The phytohormone response elements included elements that respond to ETH (ERE), ABA (ABRE, ABRE2, ABRE3a, ABRE4, and CARE), IAA (AuxRE and TGA-element), gibberellins (GARE-motif, P-box, and TATC-box), jasmonic acid (CGTCA- 
motif and TGACG-motif), and salicylic acid (TCA-element). The light response elements included the ACA-motif, GT1-motif, TCT-motif, chs-CMA1a, and Box 4. Other elements, such as lycopersicon esculentum cis-acting regulatory element (CAAAGATATC), which is involved in circadian control and cell cycle regulation, were also predicted. Detailed information on the cis-elements is shown and listed in Figure 1 and Table S3.

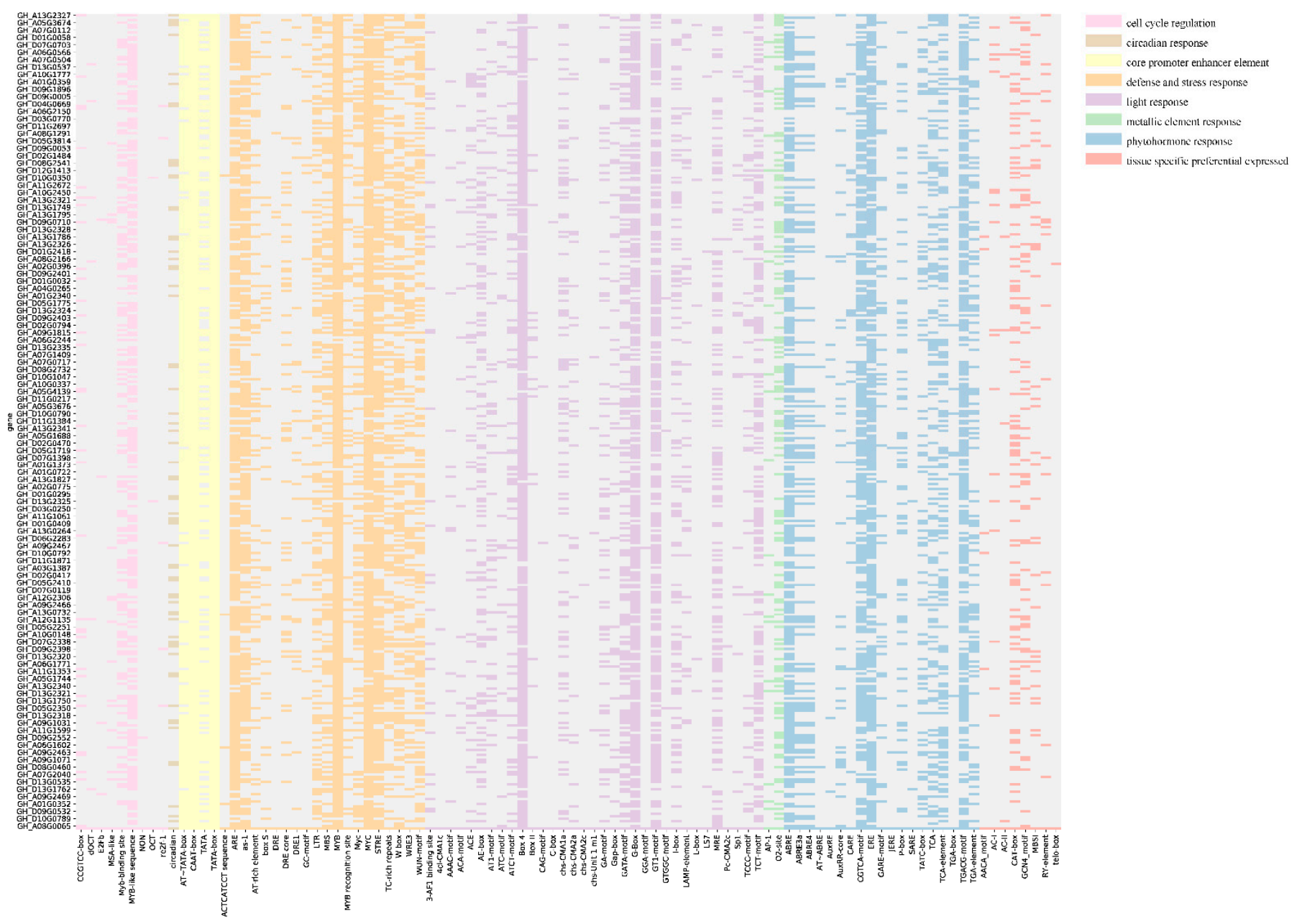

Figure 1. Cis-elements in the promoters of GhACOs. The cis-elements with similar functions are shown in the same blocks with the same color.

\subsection{Duplication Events and Selection Pressure Analysis of ACO Genes in Cotton}

To study the replication and expansion mechanisms of $A C O$ genes in cotton, data on intragenomic duplications were analyzed. A total of 101, 96, 100, and 98 gene pairs were identified as intragenomic duplications in $G a, G r$, the At subgenome of $G h$, and the Dt subgenome of $G$, respectively (Figure 2 and Table S4). Among the duplication events, WGD $(51.90 \%)$ and tandem duplication $(24.30 \%)$ were the major drivers of the formation of these cotton $A C O$ genes. The nonsynonymous substitution rate (Ka)/synonymous substitution rate (Ks; Ka/Ks) values of the duplicated gene pairs in $G a, G r$, the At subgenome of $G h$, and the Dt subgenome of $G h$ ranged from 0.057 to 1.106 (average 0.254 ), 0 to 0.818 (average 0.219 ), 0 to 0.959 (average 0.225 ), and 0.056 to 0.855 (average 0.228 ), respectively.

Intergenomic duplication events between $G a$ and $G r ; G a$ and the At subgenome of $G h$; Gr and the Dt subgenome of Gh; and the At and Dt subgenomes of Gh were detected using MCScanX. The numbers of intergenomic duplication gene pairs identified were 112, 108, 119, and 110, respectively (Figure 2 and Table S4). The Ka/Ks values of the intergenomic pairs between $G a$ and $G r$ ranged from 0.061 to 1.058 (average 0.322); those between $G a$ and the At subgenome of Gh ranged from 0.054 to 1.920 (average 0.462); those between $G r$ and 
the Dt subgenome of Gh ranged from 0.068 to 1.958 (average 0.428); and those between the At and Dt subgenomes of Gh ranged from 0.050 to 0.977 (average 0.329 ).

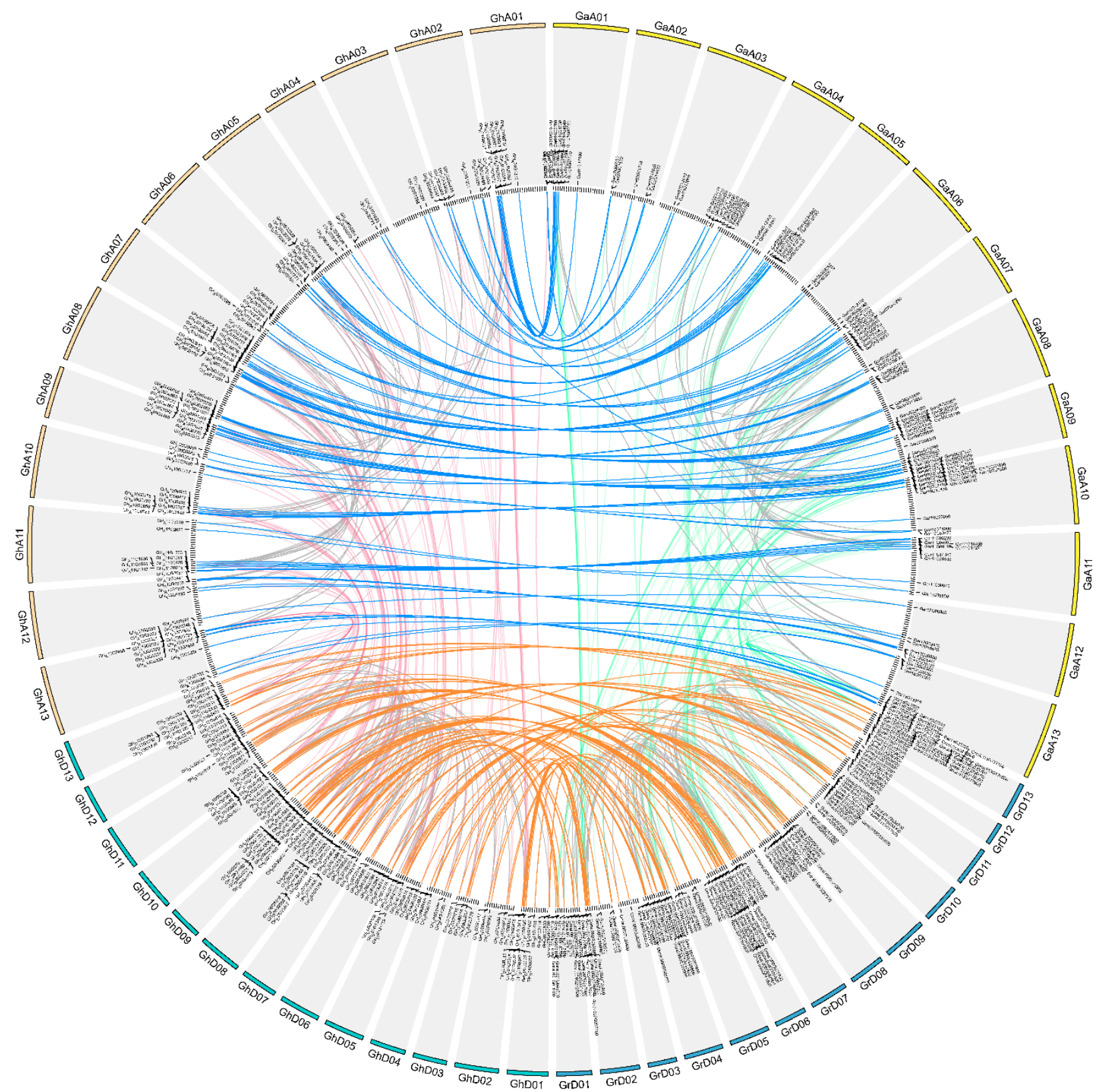

Figure 2. Collinear ACO gene pairs in cotton. Yellow, blue, orange, and green represent the chromosomes of $G a, G r$, and the At and Dt subgenomes of $G$, respectively. Gray lines represent intragenomic gene pairs, while other colors represent intergenomic gene pairs.

\subsection{Expression and Co-Expression Patterns of GhACOs}

Using the available transcriptome data, the expression characteristics of GhACOs in different tissues were determined. Thirty-five GhACOs, such as GhACO180_At (GH_A06G1771) and GhACO181_Dt (GH_D05G1775), were widely expressed in various tissues, including anther, bract, filament, leaf, petal, pistil, root, sepal, stem, and torus tissues as well as in ovules and fibers at different developmental stages (Figure S3 and Table S5). Nineteen genes, such as GhACO275_At (GH_A02G1448) and GhACO269_Dt (GH_D09G0980), showed no detectable expression in any tissue (Figure S3 and Table S5). Other genes expressed in only some of these tissues, such as GhACO112_Dt (GH_D09G1767), presented high expression in anthers, bracts, filaments, petals, pistils, roots, sepals, and toruses but no 
expression in ovules, fibers, leaves, or stems (Figure S3 and Table S5). The expression levels of GhACOs were also explored under drought (PEG 6000), salt $\left(\mathrm{NaCl}, 400 \mathrm{mmol} \cdot \mathrm{L}^{-1}\right)$, cold $\left(4^{\circ} \mathrm{C}\right)$, and hot $\left(37^{\circ} \mathrm{C}\right)$ stresses. According to a standard mean expression level (FPKM) greater than 1, it was found that 110,101, 95, and 106 GhACOs with different expression patterns were involved in the responses to drought, salt, cold, and hot stresses, respectively (Figure 3 and Table S6).

a

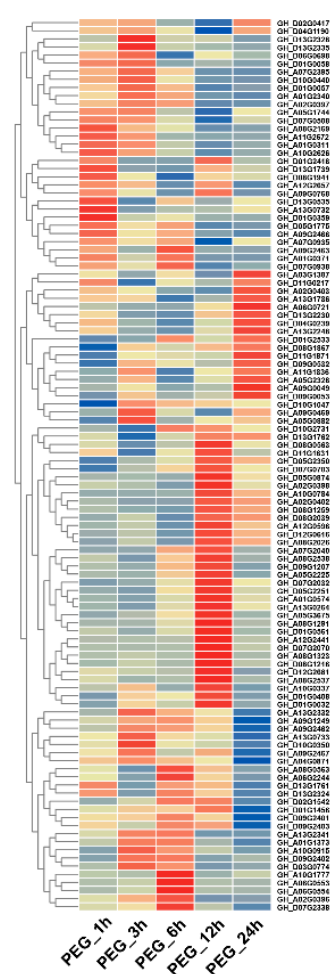

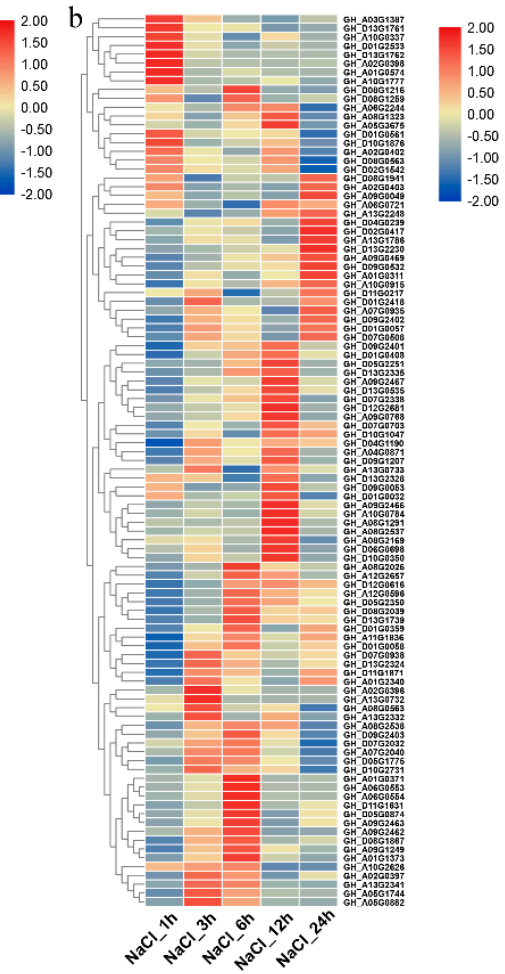
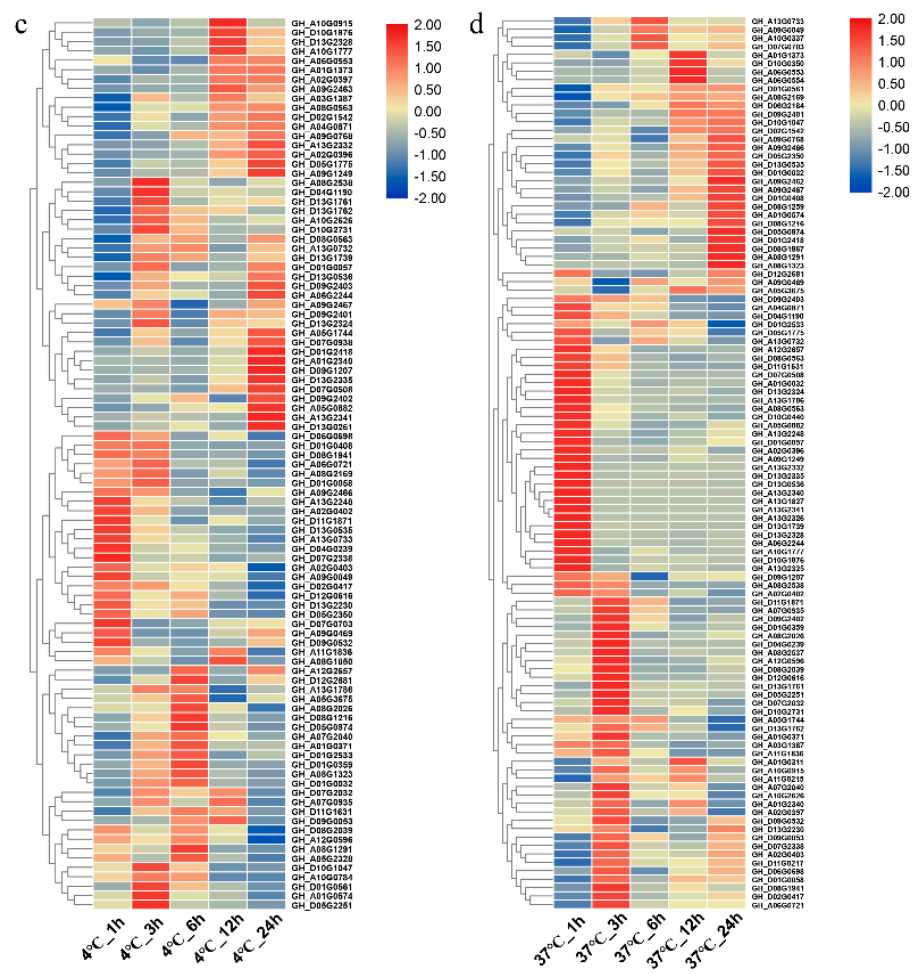

Figure 3. Expression patterns of GhACOs under drought, salt, cold, and heat stresses, (a): drought stress condition, (b): salt stress condition, (c): cold stress condition, $(\mathbf{d})$ : heat stress condition.

Through co-expression analysis, we found that genes such as GhACO110_Dt (GH_D01G2533), GhACO52_At (GH_A08G2537), GhACO187_At (GH_A07G0935), GhACO47_At (GH_A09G1249), and GhACO21_Dt (GH_D05G2251) could be co-expressed with 227 genes in different modules (Figure 4 and Table S7). A large number of genes belonging to the major intrinsic protein (MIP) superfamily, which consists of membrane channels that selectively transport water, small neutral molecules, and ions transferred between cells, were discovered to be co-expressed with GhACOs (Figure 4 and Table S7). RRM_SF superfamily genes, also known as RNA binding domain (RBD) or ribonucleoprotein domain (RNP), were also found to be co-expressed with GhACOs (Figure 4 and Table S7). Genes belonging to WRKY transcription factor families (GH_D07G1505) that were related to salt stress or antifungal activities (GH_D02G1545 and GH_D06G1400) were also shown to be co-expressed with GhACOs (Figure 4 and Table S7).

\subsection{Function Determination of GhACO106_At on Flowering Time}

By analyzing the transcriptome data of upland cotton at different stages of maturation [38], we found that GhACO106_At (GH_A09G0769) showed clear differences in expression in early-maturing and late-maturing cotton varieties. In this research, the expression characteristics of GhACO106_At were further confirmed by qRT-PCR. The qRT-PCR results showed that the expression level of GhACO106_At in the early-maturing variety (Yanzao2) was higher than that in the late-maturing variety (STS458) at the same developmental stages. Furthermore, the expression level of GhACO106_At increased with 
the development of flower bud differentiation in Yanzao2 but showed no significant change in STS458 (Figure 5a).

a

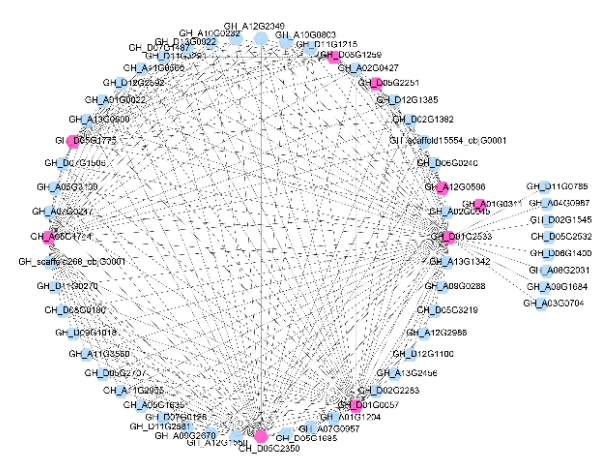

$\mathrm{c}$

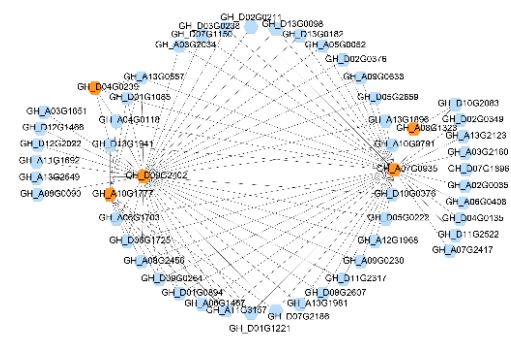

b

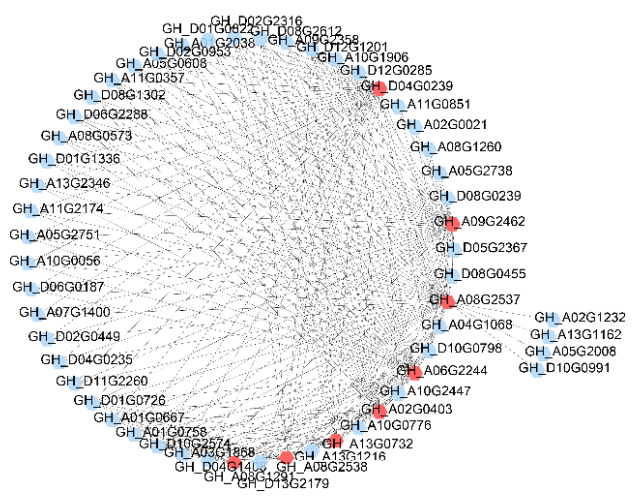

d

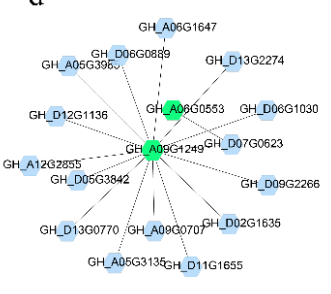

e

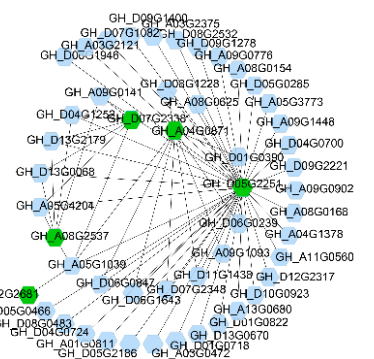

Figure 4. Co-expression networks of GhACOs. (a-e) Representative modules. Pink, red, orange, and green circles are GhACOs, and blue circles are the genes co-expressed with GhACOs. 

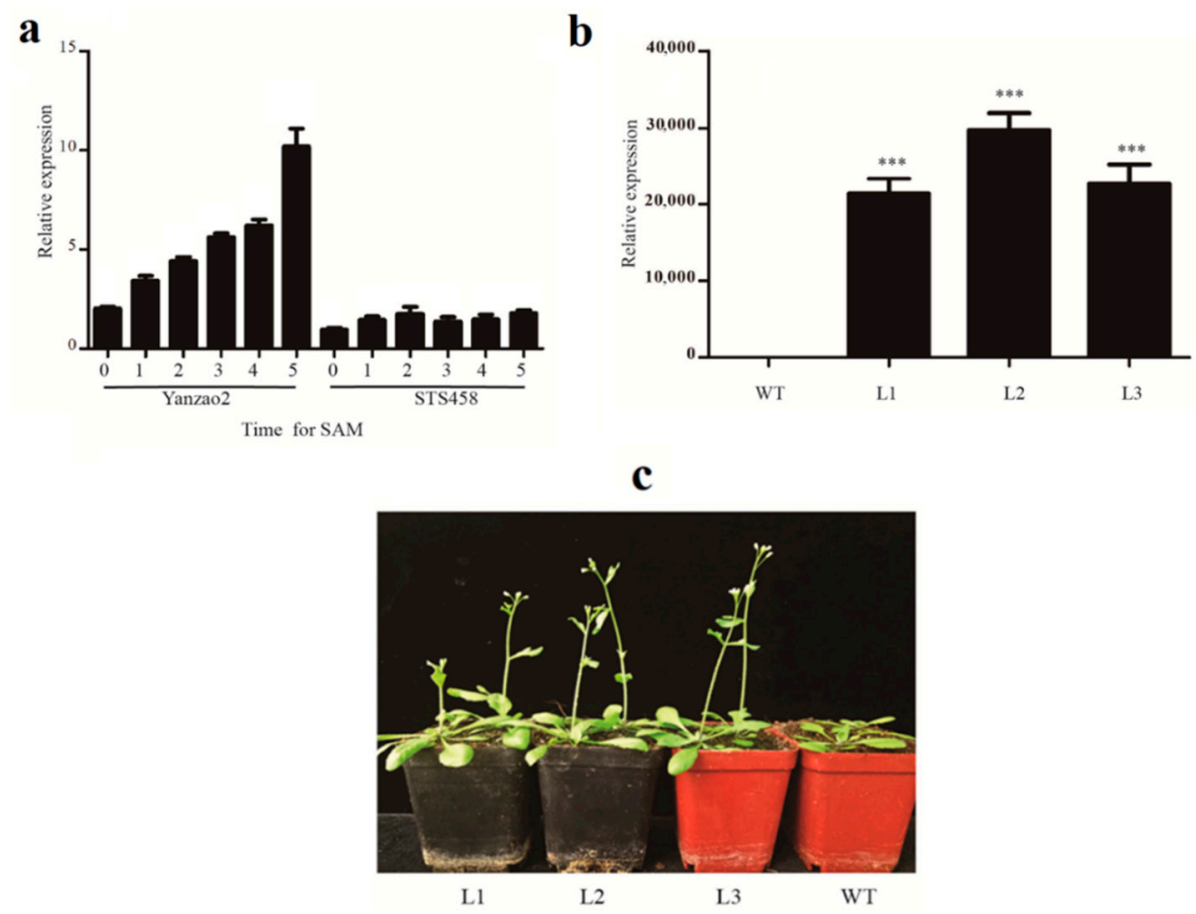

Figure 5. The expression of GhACO106_At increased with the development process of flower bud differentiation in the early-maturing variety (Yanzao2), and the overexpression of GhACO106_At in Arabidopsis caused early flowering. (a) GhACO106_At expression levels in cotton varieties with different maturation phenotypes and different shoot apical meristem (SAM) stages. Labels 0, 1, 2, 3, 4 , and 5 indicate shoot apices in the two-cotyledon expanded stage and the first, second, third, fourth, and fifth expanded true leaf stages, respectively. (b) Verification of Arabidopsis lines positive for GhACO106_At transfer via PCR. WT: wild type; L1-L3: transgenic lines; Student's $t$-test: ${ }^{* * *} p<0.001$. (c) Phenotypes of transgenic and WT Arabidopsis lines.

To further investigate the function of GhACO106_At in cotton maturation, the GhACO106_At overexpression assay was performed in Arabidopsis, and $\mathrm{T}_{3}$ transgenic plants were used for phenotypic analysis (Figure 5b). Compared with the wild type (WT), all the independent transgenic lines showed relatively early flowering, and their numbers of rosette leaves were significantly reduced (Figure $5 \mathrm{c}$ and Table 1 ). This result indicated that GhACO106_At may play an important role in cotton maturity.

Table 1. Rosette leaf number at bolting in transgenic and WT Arabidopsis.

\begin{tabular}{cccc}
\hline Line & Number of Plants & Flowering Time (Days after Sowing) & Number of Rosette Leaves (Mean \pm SD) \\
\hline 1 & 32 & $27.0 \pm 0.44^{*}$ & $9.75 \pm 0.87^{* * *}$ \\
\hline 2 & 30 & $27.7 \pm 0.66^{*}$ & $10.55 \pm 0.84^{* * *}$ \\
\hline 3 & 28 & $27.3 \pm 0.53^{*}$ & $10.04 \pm 0.84^{* * *}$ \\
\hline WT & 30 & $32.8 \pm 0.47$ & $11.93 \pm 0.80$ \\
\hline
\end{tabular}

1-3: Transgenic lines. WT: wild type. Student's $t$-test: ${ }^{*} p<0.05 ;{ }^{* * *} p<0.001$.

\subsection{Function Analysis of GhACO106_At under Salt Stress}

To further understand the function of GhACO106_At, transgenic Arabidopsis line L2, which showed the highest GhACO106_At expression level, was selected for a more detailed analysis. The L2 transgenic and WT seedlings were grown in 1/2 MS medium for 8 days. Compared to the WT, the L2 seedlings exhibited significantly longer primary roots and many more lateral roots (Figure $6 \mathrm{a}, \mathrm{b}$ ). These results suggested a positive role of GhACO106_At in plant root development and therefore a presumed role of this gene 
in mediating stress tolerance. We then investigated the potential effects of this gene by performing salt treatment. First, the germination of L2 and WT seeds was evaluated in media with various $\mathrm{NaCl}$ concentrations. In normal and $50 \mathrm{mmol} \cdot \mathrm{L}^{-1} \mathrm{NaCl}$ media, no obvious effect or difference was observed between transgenic Arabidopsis and the WT. On treatment with $\mathrm{NaCl}$ concentrations of $100 \mathrm{mmol} \cdot \mathrm{L}^{-1}$ or higher, the transgenic plants showed significantly higher germination percentages than the WT plants $(p<0.05$; Figure 6c). Furthermore, the transgenic Arabidopsis plants had longer roots and more lateral roots than WT Arabidopsis plants on all tested conditioned media (Figure 6d,e). These results illustrated the positive role of GhACO106_At in seed germination and root development. To precisely explore the effects of GhACO106_At under stress, the proline and MDA contents of 8-day-old transgenic Arabidopsis L2 line and WT plants were then investigated. Proline was induced by $\mathrm{NaCl}$ in both GhACO106_At and WT seedlings (Figure 6f). Moreover, as the salt concentration increased, the change in proline content in L2 was more significant than that in WT (Figure 6f). The MDA content was not obviously different between transgenic Arabidopsis and WT plants in normal and $50 \mathrm{mmol} \cdot \mathrm{L}^{-1} \mathrm{NaCl}$ media (Figure 6g). Furthermore, the MDA content of transgenic Arabidopsis plants was significantly lower than that of WT plants in media with 100 and $150 \mathrm{mmol} \cdot \mathrm{L}^{-1} \mathrm{NaCl}$ (Figure 6g). These results demonstrate that the overexpression of GhACO106_At can significantly enhance the resistance of plants to salt stress. 

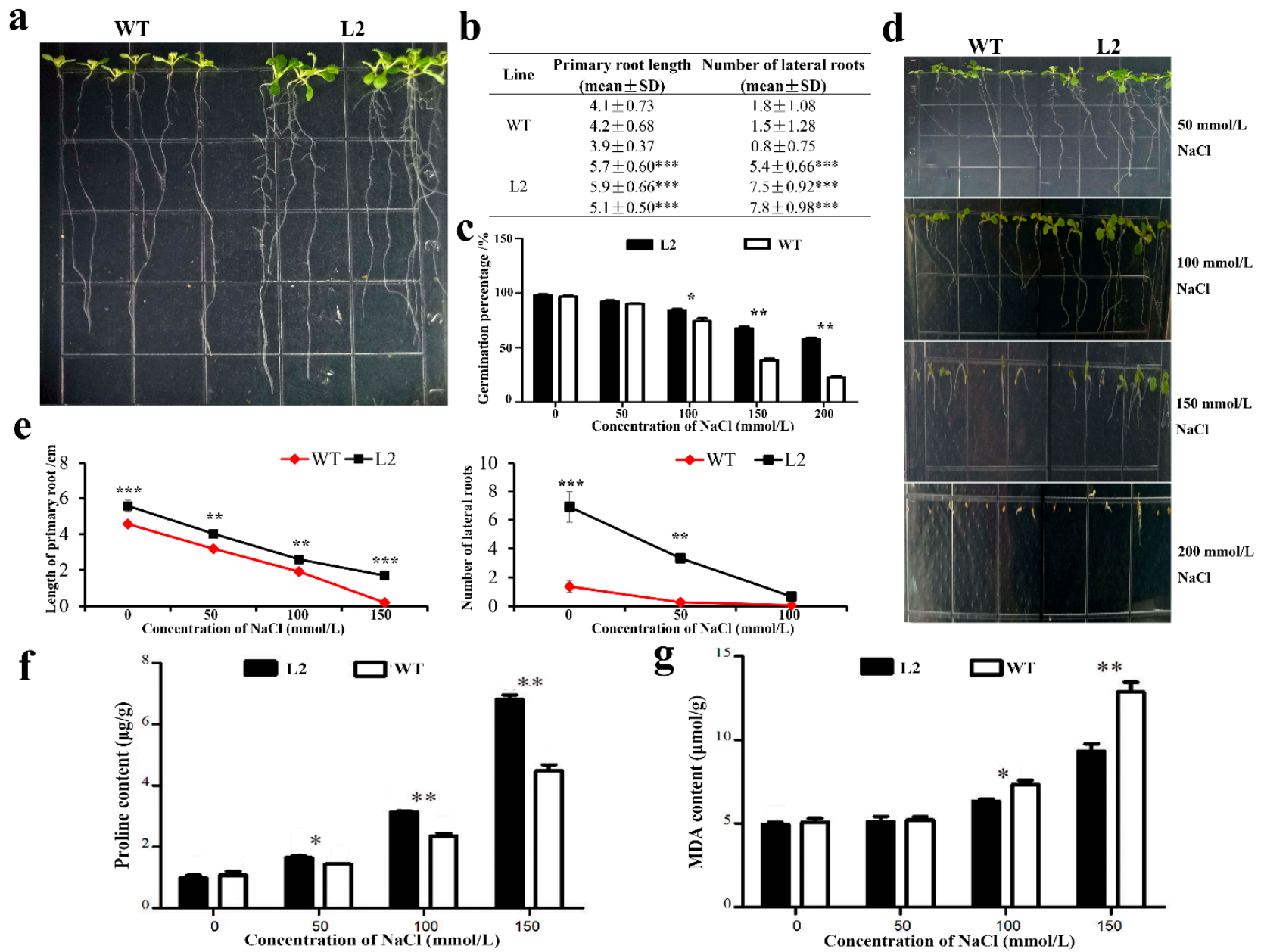

Figure 6. GhACO106_At increased salt stress tolerance in transgenic Arabidopsis. (a) Root phenotype of 8-day-old WT and L2 transgenic seedlings; (b) statistical data of primary roots and lateral roots of WT and L2 transgenic seedlings; (c) seed germination rate of WT and L2 transgenic seedlings under control and various $\mathrm{NaCl}$ treatments; (d) root phenotypes of 8-day-old WT and L2 transgenic seedlings under various $\mathrm{NaCl}$ treatments; (e) primary root lengths and the number of lateral roots of WT and L2 transgenic seedlings under control and various $\mathrm{NaCl}$ treatments; (f) proline contents of WT and L2 transgenic seedlings under control and various $\mathrm{NaCl}$ treatments; (g) MDA contents of WT and L2 transgenic seedlings under control and various $\mathrm{NaCl}$ treatments. L2: transgenic line, WT: wild type. Student's $t$-test: ${ }^{*} p<0.05$; ${ }^{* *} p<0.01$; $* * * p<0.001$.

\section{Discussion}

\subsection{Gene Duplication Events and Positive Selection Have Led to Large Numbers and Different Functions of ACO Genes in Cotton}

Due to their increased amount of genetic material, polyploid plants show higher degrees of heterozygosity and genetic diversity as well as greater evolutionary adaptability [39]. For example, natural tetraploid Arabidopsis thaliana shows increased potassium uptake and salinity tolerance [40], and the polyploidization of rice and citrus alters the expression of hormone-related genes, making the plants more resistant to saline-alkali conditions and drought [41]. The Gossypium genus has experienced rapid speciation and differentiation events, as well as hybridization and polyploidization events. Allotetraploid upland cotton, which has excellent agricultural traits, was the outcome of such natural hybridization. Comparative analysis among the whole-genome sequences of G. hirsutum, G. arboretum, and G. raimondii revealed that polyploidization events occurred both before and after the AADD lineage emerged and led to the expansion of the cotton genome [32,34]. In the present study, we have identified $320 A C O$ genes belonging to tetraploid cotton species G. hirsutum while 187 and 181 ACO genes were identified in each diploid cotton 
species, G. arboreum and G. raimondii, respectively. Therefore, compared with previous studies (11 ACO genes in pear and 9 ACO genes in melon) [42], cotton has a very large number of $A C O$ members. Further analysis showed that a huge number of whole-genome duplication events (WGD) and tandem duplication events (TD) were found in cotton ACO genes. On the other hand, we found that a total of 227 ACO genes in the G. hirsutum genome have collinear genes in G. arboretum and G. raimondii. These results suggested that WGD and TD events play a leading role in the large-scale expansion of $A C O$ genes in diploid cotton species, and they conserved well in allopolyploidization events. Selection pressure analyses further revealed the evolution process of the $A C O$ genes in cotton. The $\mathrm{Ka} / \mathrm{Ks}$ analysis showed that the $\mathrm{Ka} / \mathrm{Ks}$ values between $\mathrm{G} a$ and the At subgenome of $G h$, $\mathrm{Gr}$ and the Dt subgenome of $G h$, and the At and Dt subgenomes of $G h$ were larger than the value between $G a$ and $G r$, indicating more positive selection after allopolyploidization than before allopolyploidization in cotton. Altogether, we surmised that the main reason for the existence of so many ACO genes in cotton is probably gene duplication events and that positive selection after allopolyploidization further drove the development of diverse functions and the retention of $A C O$ genes in cotton.

\subsection{GhACO106_At Probably Regulates Cotton Flowering Time}

Promoters contain diverse varieties of important cis-elements that can accurately bind to template DNA to stimulate or inhibit gene transcription. Therefore, the functions of genes can be inferred by cis-element identification. In this investigation, the promoter analysis of GhACOs revealed that the cis-elements of GhACOs can respond to stress, phytohormones, light, and circadian factors, indicating the possible involvement of GhACOs in these processes (Figure 1). For GhACO106_At, it also contained the cis-regulatory element that responds to light, which can affect the growth periods of crops. The expression of GhACO106_At shows clear differences in expression in early- (Yanzao2) and late-maturing cotton (STS458; Figure 5a). These results further confirmed the function of this gene in early- and late-maturing varieties. Because flowering time is an important indicator of early and late maturity, we predicted that GhACO106_At may regulate flowering time. To further investigate the function of GhACO106_At, transgenic Arabidopsis lines overexpressing GhACO106_At were obtained, and it was discovered that all three transgenic lines had an early flowering phenotype (Figure $5 \mathrm{~b}, \mathrm{c}$ ). Furthermore, previous studies have confirmed that ethylene can regulate vegetative growth and flower formation in plants [43-47]. For example, ethylene can enhance photosynthetic performance, promote vegetative growth, and increase the number of soybean flowers [47]. Therefore, based on the gene expression results and the phenotype results obtained in transgenic Arabidopsis as well as reports on the regulatory functions of ethylene in plant growth and development, it can be inferred that GhACO106_At probably functions in the regulation of cotton flowering time by controlling the synthesis of ethylene.

\subsection{GhACO106_At Regulates the Growth of Roots and Salt Stress Resistance}

Studies have reported that salt stress has a significant inhibitory effect on the germination of seeds. For cabbage, the germination and germination rate were significantly affected by different concentrations of salt stress [48]. In previous studies on sunflower and Arabidopsis, it was reported that ethylene can stimulate seed germination by inhibiting the effect of ABA $[49,50]$. In Stylosanthes humilis, within a given $\mathrm{pH}$ condition, the energy metabolism and embryo growth potential of seeds under salt stress may be regulated by the flexibility provided by the biosynthesis of ABA and ethylene [51]. Furthermore, in Arabidopsis, Yu et al. found that the nucleoplasm distribution of COP1 was antagonistically regulated by salt stress and ethylene, and then resulted in the controlling of seed germination via the COP1-mediated down-regulation of HY5 and ABI5 [52]. In this study, under the normal medium without salt stress, the germination rate of GhACO106_At transgenic Arabidopsis and the wild type is almost the same. However, with the increment of salt concentration, the germination rate of the wild-type Arabidopsis was significantly lower than that of the 
wild type, indicating that GhACO106_At could promote the germination under salt stress. Likewise, the change in seed germination in our results, we speculate, was also mediated by ethylene, and the biosynthesis of ethylene was regulated by GhACO106_At.

As roots are the functional organ responsible for nutrient acquisition, soil anchorage, and environmental interactions, their proper growth and development are critical for plants. Ethylene has been reported to play an important role in the growth and development of Arabidopsis roots, including the elongation of the main roots and the formation of lateral roots. In Arabidopsis, studies found that the ethylene-insensitive Arabidopsis mutant eto1-1 exhibits a shorter primary root length; the enhancement of ethylene synthesis could promote the lateral root primordia's initiation; and the coordinated complex consisting of EIN3/EIL1 and RHD6/RSL1, which is activated by ethylene, can promote root hair growth [53-55]. Besides, salinity is the most important environmental factor that inhibits root water uptake and slows the growth of plants. Studies have shown that ethylene acts as a signal of salt stress [56]. In Arabidopsis, salt stress increased the detectable levels of emanated ethylene as well as the expression of $A C S$ genes encoding ACS2 and ACS7 transcripts [57]. In cotton, the expression of multiple ACOs is also induced by salt stress [58]. As for GhACO106_At in this research, compared to WT, the L2 seedlings exhibited significantly longer primary roots and much more lateral roots. This result suggested a positive role of GhACO106_At in plant root development, and this role is possibly implemented by regulating the biosynthesis of ethylene. Moreover, with the increase in salt concentration, the proline content of L2 increased more significantly than that of WT, and the content of MDA was significantly lower than that of WT in the medium of 100 and $150 \mathrm{mmol} \cdot \mathrm{L}^{-1} \mathrm{NaCl}$. These results further demonstrated that overexpression of GhACO106_At can significantly enhance the resistance of plants to salt stress.

Altogether, our results revealed that the overexpression of GhACO106_At can promote seed germination and improve plant root development under normal and salt stress environments, as illustrated by higher germination rates, stronger root growth, and less damage degree of plants. In view of previous studies about the function of ethylene in seed germination, root growth, and salt stress, we speculate that the realization of all functions of GhACO106_At in this study may also be mediated by its regulation of ethylene biosynthesis.

\section{Materials and Methods}

\subsection{Identification and Phylogenetic Analysis of ACO Genes in Cotton}

The ZJU.V2, WHU and JGI versions of the protein databases of G. hirsutum, G. arboretum, and G. raimondii, respectively, were downloaded from the CottonGen website (https:/ / www.cottongen.org/data/download, accessed on 12 May 2020) [59]. The two relevant domain files, DIOX_Nhmm (PF14226) and 2OG-FeII_Oxy.hmm (PF03171), were downloaded from the Pfam website (http:/ / pfam.xfam.org/, accessed on 12 May 2020) [60] and used as queries to search against the three Gossypium species protein databases using HMMER3 (http:/ /hmmer.org/, accessed on 15 May 2020) with an $e$-value threshold of $1 \times 10^{-5}$. The Hmmsearch hits were submitted to the Pfam website to confirm those putative ACOs that contained the two target domains. The protein sequences of the ACOs were aligned using Clustal Omega with the default parameters (https:/ / www.ebi.ac.uk/Tools/ $\mathrm{msa}$ / clustalo/, accessed on 22 May 2020). The resulting alignments were used as the input file for MrBayes v3.2.5 to construct the corresponding phylogenetic tree with the following settings: the evolutionary model set to the GTR substitution model, gamma-distributed rate variation across sites, Ngen $=1,000,000$, and Samplefreq $=100$ [61]. The theoretical Mw, pI, and GRAVY values of the identified ACOs in this research were calculated at the ExPASy website (http:/ / web.expasy.org/protparam/, accessed on 26 May 2020) [62]. The lengths and positions of the DIOX_N and 2OG-FeII_Oxy domains of each ACO gene were predicted using PfamScan (https:/ / www.ebi.ac.uk/Tools/pfa/pfamscan/, accessed on 2 June 2020) and displayed in the phylogenetic tree using iTOL v4 (https: / itol.embl.de/, accessed on 5 June 2020) [63]. The conserved motifs in ACOs were identified with MEME 
v5.0.5 (http:/ / meme-suite.org/tools/meme, accessed on 8 June 2020) with the following parameters: site distribution, 0 or 1 occurrence per sequence; number of motifs, 10; and width between 6 and 50 [64].

\subsection{Analysis of ACO Gene Duplication Event and Selection Pressure in Cotton}

BlastP ( $E<1 \times 10^{-10}$, top five matches and $\mathrm{m} 8$ format output), Dupgen_finder (https:/ / github.com/qiao-xin/DupGen_finder, accessed on 10 June 2020), and MCScanX (with default parameters) were employed to search for intragenomic and intergenomic gene duplications $[65,66]$. The protein sequences and coding sequences of each gene pair were aligned using MAFFT software and transformed into an AXT format via the pParaAT pipeline $[67,68]$. The Ka, Ks, and evolutionary constraint $(\mathrm{Ka} / \mathrm{Ks})$ values between each gene pair were calculated with Kaks_calculator (v2.0) using the method of Nei and Gojobori $[69,70]$.

\subsection{Expression and Co-Expression Analysis of GhACOs}

Online available transcriptome data on tissue-specific and abiotic stress-related expression were downloaded from the NCBI SRA database (accession numbers PRJNA490626 and PRJNA532694). The RNA-seq data were analyzed based on the methods of Chen et al. [71]. Specifically, the raw RNA-seq reads were filtered using Trimmomatic with the default parameters, and clean RNA-seq reads were obtained. The clean RNA-seq reads were mapped to the reference genome using HISAT2, and SAM format data were obtained. The SAM format data were transformed into BAM format data by SAMtools. The BAM files were assembled into transcripts, and fragments per kilobase of transcript per million mapped reads (FPKM) values were generated using StringTie. Co-expression networks were constructed using the WGCNA package (v1.69) [72], and the networks were visualized with the help of Cytoscape (v3.7.2; http:/ / www.cytoscape.org/, accessed on 5 March 2021).

\subsection{Expression Analysis of GhACO106_At}

The upland cotton varieties Yanzao2 and STS458 were planted in the experimental field of the Cotton Research Institute of the Chinese Academy of Agricultural Sciences and grown under routine field management methods. After the cotyledon flattened, the apical buds of Yanzao2 and STS458 were collected at the first, second, third, fourth, and fifth true leaf flattening stages. The TRIzol extraction reagent (Tiangen Biochemical Technology (Beijing) Co., Ltd.) was used to extract total RNA from the bud samples. A PrimeScript RT reagent kit with gDNA Eraser (Perfect Real Time, TaKaRa, China) was used to synthesize cDNA. Specific primers for GhACO106_At were designed with Oligo7 for real-time fluorescent quantitative RT-PCR. The forward primer was 5'-TGAAAGCGCTGGTAGATTCGGG-3', and the reverse primer was 5'-TCATTGTTGGTGGGGCTTCCAG-3'. Each experiment was designed with three biological and three technical replicates. Quantitative RT-PCR was performed on an ABI 7500 Real-Time PCR system analyzer (Applied Biosystems) using UltraSYBR ${ }^{\circledR}$ Mixture (Low ROX; CWBIO). The $20 \mu \mathrm{L}$ reaction volume contained the following components: $10 \mu \mathrm{L}$ of UltraSYBR Mixture (Low ROX; $2 \times$ ), $0.4 \mu \mathrm{L}$ of the PCR forward primer $(10 \mu \mathrm{M}), 0.4 \mu \mathrm{L}$ of the PCR reverse primer $(10 \mu \mathrm{M}), 0.8 \mu \mathrm{L}$ of cDNA, and $8.4 \mu \mathrm{L}$ of $\mathrm{ddH}_{2} \mathrm{O}$. The amplification was performed using the following protocol: a pre-denaturation step at $95^{\circ} \mathrm{C}$ for $10 \mathrm{~min}$; 40 cycles of $\left(95^{\circ} \mathrm{C}\right.$ for $10 \mathrm{~s}, 60^{\circ} \mathrm{C}$ for $30 \mathrm{~s}$, and $72{ }^{\circ} \mathrm{C}$ for $32 \mathrm{~s}$ ); a melting curve step at $95{ }^{\circ} \mathrm{C}$ for $15 \mathrm{~s}, 60{ }^{\circ} \mathrm{C}$ for $1 \mathrm{~min}, 95^{\circ} \mathrm{C}$ for $15 \mathrm{~s}$, and $60^{\circ} \mathrm{C}$ for $15 \mathrm{~s}$. The cotton endogenous histone-3 (NCBI gene ID: 107950429) and Arabidopsis endogenous Actin 2 (NCBI gene ID: 821411) were used as the internal standard to normalize the relative expression levels of GhACO106_At in cotton and Arabidopsis, respectively. Each experiment was designed for three biological replicates. The results of fluorescence quantitative dissolution curve analysis are shown in Supplementary Figure S4. 


\subsection{Screening of GhACO106_At overexpressing Arabidopsis}

The open reading fragment (ORF) of GhACO106_At was inserted into a 35S promoterdriven vector (pBI121) to construct the 35S:GhACO106_At vector. This vector was then transformed into the Agrobacterium LBA4404 strain, which in turn was used to transform Arabidopsis via the floral-dip method [73]. The screening and verification of positive plants from $T_{0}$ generation seeds to $T_{3}$ generation seeds were performed based on the methods of Gu et al. [74].

\subsection{Salt Stress Treatments}

WT and GhACO106_At-overexpressing Arabidopsis seeds were planted in plates with $1 / 2 \mathrm{MS}$ media and different salt treatments $\left(50 \mathrm{mmol} \cdot \mathrm{L}^{-1}, 100 \mathrm{mmol} \cdot \mathrm{L}^{-1}, 150 \mathrm{mmol} \cdot \mathrm{L}^{-1}\right.$, and $200 \mathrm{mmol} \cdot \mathrm{L}^{-1} \mathrm{NaCl}$ ). The plates were stratified at $4{ }^{\circ} \mathrm{C}$ for 2 days in darkness and then kept in a growth chamber under controlled conditions $\left(22^{\circ} \mathrm{C}, 70 \%\right.$ relative humidity, and a $16 / 8 \mathrm{~h}$ light/dark cycle). On the 8th day after the seeds were planted, their germination and root length were recorded.

\subsection{Statistical Analyses}

The $2^{-\Delta \Delta C T}$ method was used to analyze the experimental results to calculate relative expression of GhACO106_At at the first, second, third, fourth, and fifth true leaf flattening stages of Yanzao2 and STS458 [75]. Root length determination was independently performed on WT and L2 plants in 3 media, each of which contained 10 seedlings. Germination was recorded when the embryo broke through the seed coat, and the standard for germination was considered a germinated embryo length exceeding half of the seed length. The percentage of the total germination rate was determined as the ratio of the number of germinated seeds $(\mathrm{n})$ to the number of tested seeds $(\mathrm{N})$ multiplied by $100(100 \times \mathrm{n} / \mathrm{N})$. The determination of proline and MDA contents was performed based on the Beijing Solebold Biochemical Kit manual and was repeated three times. The degree of the differences between transgenic and WT Arabidopsis under the same salt concentration was evaluated with independent samples t-tests. Microsoft Excel was used to perform the $t$-tests (significant difference, $p<0.05$; very significant difference, $p<0.01$ ).

\section{Conclusions}

In the current study, cotton $A C O$ genes were identified from G. hirsutum, G. arboretum, and G. raimondii. In total, 332 GhACOs, 187 GaACOs, and 181 GrACOs were identified, and their physicochemical properties, domain architectures, phylogenetic relationships, syntenic relationships, and spatiotemporal expression were analyzed. These $A C O$ genes were divided into four subgroups based on phylogenetic analysis. The upstream analysis of GhACOs revealed that elements in the promoters of these $A C O$ genes respond to stress, phytohormones, light, and circadian factors, indicating the possible involvement of GhACOs in these processes. Gene duplication analysis showed that WGD and tandem duplication events were the major forces driving the generation of $A C O$ genes. The expression and co-expression analyses illustrated that most GhACOs were not only widely expressed in various tissues but were also coexpressed with other genes in response to salt and drought stress. Furthermore, the functional investigation of GhACO106_At showed a significantly reduced flowering time and an increased salt resistance in GhACO106_At transgenic Arabidopsis, suggesting that GhACO106_At probably participates in the regulation of flowering time and the response to salt stress.

Supplementary Materials: The following supplementary materials are available online at https:/ / www.mdpi.com/article/10.3390/plants10081699/s1: Figure S1: Phylogenetic relationships and subfamily designations of ACO proteins from G. hirsutum, G. arboreum, and G. raimondii; Figure S2: Conserved motifs in cotton ACO proteins; Figure S3: Expression characteristics in different tissues of GhACOs; Figure S4: The results of RT-PCR fluorescence quantitative dissolution curve analysis in cotton and Arabidopsis of GhACO106_At; Table S1: Information on ACO 
genes in cotton; Table S2: Details of conserved motifs in cotton ACO proteins; Table S3: Information on cis-elements identified in the promoters of GhACOs; Table S4: Duplication events of ACO genes in cotton species; Table S5: Expression patterns of GhACOs in different cotton tissues; Table S6: Expression characteristics of GhACOs under various stresses; Table S7: List of genes coexpressed with GhACOs.

Author Contributions: H.W. and Y.X. performed the experiments and wrote the manuscript; P.C., P.H. and F.W. collected and analyzed all the sequences and transcriptomics; Y.X. and L.S. worked in cotton culture processing and RNA extraction; Y.Y. designed the experiments. All authors have read and agreed to the published version of the manuscript.

Funding: This research was funded by the National Key R\&D Program of China (2020YFD1001004), Open Fund of the State Key Laboratory of Cotton Biology (CB2021A24), and the Young and Middleaged Science and Technology Innovation Leading Talents Program of Xinjiang Production and Construction Corps (2020CB010).

Institutional Review Board Statement: Not applicable.

Informed Consent Statement: Not applicable.

Data Availability Statement: All the genome sequences analyzed in this project were retrieved from Cottongen (https:/ / www.cottongen.org/ (accessed on 17 August 2021)), the JGI database (https: / / www.phytozome.net (accessed on 17 August 2021)), and the National Center for Biotechnology Information (NCBI) database (https:/ / www.ncbi.nlm.nih.gov/ (accessed on 17 August 2021)).

Acknowledgments: Thanks to Jose Benjamin Giron for revising the manuscript.

Conflicts of Interest: The authors declare no conflict of interest.

\section{References}

1. Hamilton, A.J.; Bouzayen, M.; Grierson, D. Identification of a tomato gene for the ethylene-forming enzyme by expression in yeast. Proc. Natl. Acad. Sci. USA 1991, 88, 7434-7437. [CrossRef]

2. Fu, B.; Wang, W.; Liu, X.; Duan, X.; Allan, A.C.; Grierson, D.; Yin, X. An ethylene-hypersensitive methionine sulfoxide reductase regulated by NAC transcription factors increases methionine pool size and ethylene production during kiwifruit ripening. New Phytol. 2021. [CrossRef] [PubMed]

3. Spanu, P.; Reinhardt, D.; Boller, T. Analysis and cloning of the ethylene-forming enzyme from tomato by functional expression of its mRNA in Xenopus laevis oocytes. EMBO J. 1991, 10, 2007-2013. [CrossRef] [PubMed]

4. Hamilton, A.; Lycett, G.; Grierson, D. Antisense gene that inhibits synthesis of the hormone ethylene in transgenic plants. Nature 1990, 346, 284-287. [CrossRef]

5. Slater, A.; Maunders, M.J.; Edwards, K.; Schuch, W.; Grierson, D. Isolation and characterisation of cDNA clones for tomato polygalacturonase and other ripening-related proteins. Plant Mol. Biol. 1985, 5, 137-147. [CrossRef] [PubMed]

6. De Martinis, D.; Mariani, C. Silencing gene expression of the ethylene-forming enzyme results in a reversible inhibition of ovule development in transgenic tobacco plants. Plant Cell. 1999, 11, 1061-1072. [CrossRef] [PubMed]

7. Chen, H.; Sun, J.; Li, S.; Cui, Q.; Zhang, H.; Xin, F.; Wang, H.; Lin, T.; Gao, D.; Wang, S.; et al. An ACC oxidase gene essential for cucumber carpel development. Mol. Plant 2016, 9, 1315-1327. [CrossRef]

8. Beatriz, C.; James, J. Molecular biology of ethylene during tomato fruit development and maturation. Plant Sci. 2008, 175, 106-113.

9. Nakatsuka, A.; Murachi, S.; Okunishi, H.; Shiomi, S.; Nakano, R.; Kubo, Y.; Inaba, A. Differential expression and internal feedback regulation of 1-aminocyclopropane-1-carboxylate synthase, 1-aminocyclopropane-1-carboxylate oxidase, and ethylene receptor genes in tomato fruit during development and ripening. Plant Physiol. 1998, 118, 1295-1305. [CrossRef]

10. Blume, B.; Grierson, D. Expression of ACC oxidase promoter-GUS fusions in tomato and Nicotiana plumbaginifolia regulated by developmental and environmental stimuli. Plant J. 1997, 12, 731-746. [CrossRef]

11. Barry, C.S.; Blume, B.; Bouzayen, M.; Cooper, W.; Hamilton, A.J.; Grierson, D. Differential expression of the 1-aminocyclopropane1-carboxylate oxidase gene family of tomato. Plant J. 1996, 9, 525-535. [CrossRef]

12. Picton, S.; Barton, S.; Bouzayen, M.; Hamilton, A.; Grierson, D. Altered fruit ripening and leaf senescence in tomatoes expressing an antisense ethylene-forming enzyme transgene. Plant J. 1993, 3, 469-481. [CrossRef]

13. Xia, Y.; Chiu, C.H.; Do, Y.Y.; Huang, P.L. Expression fluctuations of genes involved in carbohydrate metabolism affected by alterations of ethylene biosynthesis associated with ripening in banana fruit. Plants 2020, 9, 1120. [CrossRef] [PubMed]

14. Trainotti, L.; Pavanello, A.; Casadoro, G. Different ethylene receptors show an increased expression during the ripening of strawberries: Does such an increment imply a role for ethylene in the ripening of these non-climacteric fruits? J. Exp. Bot. 2005, 56, 2037-2046. [CrossRef] [PubMed]

15. Ruperti, B.; Bonghi, C.; Rasori, A.; Ramina, A.; Tonutti, P. Characterization and expression of two members of the peach 1-aminocyclopropane-1-carboxylate oxidase gene family. Physiol. Plant. 2001, 111, 336-344. [CrossRef] [PubMed] 
16. Atkinson, R.G.; Bolitho, K.M.; Wright, M.A.; Iturriagagoitia-Bueno, T.; Reid, S.J.; Ross, G.S. Apple ACC-oxidase and polygalacturonase: Ripening-specific gene expression and promoter analysis in transgenic tomato. Plant Mol. Biol. 1998, 38, 449-460. [CrossRef] [PubMed]

17. Ten Have, A.; Woltering, E.J. Ethylene biosynthetic genes are differentially expressed during carnation (Dianthus caryophyllus L.) flower senescence. Plant Mol. Biol. 1997, 34, 89-97. [CrossRef]

18. Savin, K.; Baudinette, S.; Graham, M.; Michael, M.; Nugent, G.; Lu, C.; Chandler, S.; Cornish, E. Antisense ACC oxidase RNA delays carnation petal senescence. Am. Soc. Hortic. Sci. 1995, 5, 970-972. [CrossRef]

19. Zabala, G.; Kour, A.; Vodkin, L.O. Overexpression of an ethylene-forming ACC oxidase (ACO) gene precedes the Minute Hilum seed coat phenotype in Glycine max. BMC Genom. 2020, 21, 716. [CrossRef]

20. Houben, M.; Van de Poel, B. 1-aminocyclopropane-1-carboxylic acid oxidase (ACO): The enzyme that Makes the plant hormone ethylene. Front. Plant Sci. 2019, 10, 695. [CrossRef]

21. Jia, H.; Chen, S.; Liu, D.; Liesche, J.; Shi, C.; Wang, J.; Ren, M.; Wang, X.; Yang, J.; Shi, W.; et al. Ethylene-induced hydrogen sulfide negatively regulates ethylene biosynthesis by persulfidation of ACO in tomato under osmotic Stress. Front. Plant Sci. 2018, 9, 1517. [CrossRef] [PubMed]

22. Chen, D.; Ma, X.; Li, C.; Zhang, W.; Xia, G.; Wang, M. A wheat aminocyclopropane-1-carboxylate oxidase gene, TaACO1, negatively regulates salinity stress in Arabidopsis thaliana. Plant Cell Rep. 2014, 33, 1815-1827. [CrossRef]

23. Ramadoss, N.; Gupta, D.; Vaidya, B.N.; Joshee, N.; Basu, C. Functional characterization of 1-aminocyclopropane-1-carboxylic acid oxidase gene in Arabidopsis thaliana and its potential in providing flood tolerance. Biochem. Biophys. Res. Commun. 2018, 503, 365-370. [CrossRef] [PubMed]

24. Singh, N.; Bhatla, S. Nitric oxide regulates lateral root formation through modulation of ACC oxidase activity in sunflower seedlings under salt stress. Plant Signal. Behav. 2018, 13, e1473683. [CrossRef]

25. Balague, C.; Watson, C.F.; Turner, A.J.; Rouge, P.; Picton, S.; Pech, J.C.; Grierson, D. Isolation of a ripening and wound-induced cDNA from Cucumis melo L. encoding a protein with homology to the ethylene-forming enzyme. Eur. J. Biochem. 1993, 212, 27-34. [CrossRef]

26. Zanetti, M.E.; Terrile, M.C.; Arce, D.; Godoy, A.V.; Segundo, B.S.; Casalongue, C. Isolation and characterization of a potato cDNA corresponding to a 1-aminocyclopropane-1-carboxylate (ACC) oxidase gene differentially activated by stress. J. Exp. Bot. 2002, 53, 2455-2457. [CrossRef] [PubMed]

27. Zhang, M.; Yuan, B.; Leng, P. The role of ABA in triggering ethylene biosynthesis and ripening of tomato fruit. J. Exp. Bot. 2009, 60, 1579-1588. [CrossRef] [PubMed]

28. Pogson, B.J.; Downs, C.G.; Davies, K.M. Differential expression of two 1-aminocyclopropane-1-carboxylic acid oxidase genes in broccoli after harvest. Plant Physiol. 1995, 108, 651-657. [CrossRef]

29. Chae, H.S.; Cho, Y.; Park, M.; Lee, M.; Eun, M.; Kang, B.; Kim, W. Hormonal cross-talk between auxin and ethylene differentially regulates the expression of two members of the 1-aminocyclopropane-1-carboxylate oxidase gene family in rice (Oryza sativa L.). Plant Cell Physiol. 2000, 41, 354-362. [CrossRef] [PubMed]

30. Calvo, A.P.; Nicolas, C.; Nicolas, G.; Rodriguez, D. Evidence of a cross-talk regulation of a GA 20-oxidase (FsGA20ox1) by gibberellins and ethylene during the breaking of dormancy in Fagus sylvatica seeds. Physiol. Plant. 2004, 120, 623-630. [CrossRef]

31. Xiao, G.Z.; Li, L.J.; Teng, K.; Chao, Y.H.; Han, L.B. Cloning and expression of the 1-aminocyclopropane-1-carboxylic oxidase gene from Agrostis stolonifera. Genet. Mol. Res. 2016, 15. [CrossRef] [PubMed]

32. Chen, Z.; Feng, K.; Grover, C.E.; Li, P.; Liu, F.; Wang, Y.; Xu, Q.; Shang, M.; Zhou, Z.; Cai, X.; et al. Chloroplast DNA structural variation, phylogeny, and age of divergence among diploid cotton species. PLoS ONE 2016, 11, e0157183. [CrossRef] [PubMed]

33. Wendel, J.F.; Grover, C.E. Taxonomy and Evolution of the Cotton Genus, Gossypium. Agron. Monogr. 2015, 25-44. [CrossRef]

34. Li, F.; Fan, G.; Lu, C.; Xiao, G.; Zou, C.; Kohel, R.J.; Ma, Z.; Shang, H.; Ma, X.; Wu, J.; et al. Genome sequence of cultivated upland cotton (Gossypium hirsutum TM-1) provides insights into genome evolution. Nat. Biotechnol. 2015, 335, 524-530. [CrossRef] [PubMed]

35. Binnie, J.E.; McManus, M.T. Characterization of the 1-aminocyclopropane-1-carboxylic acid (ACC) oxidase multigene family of Malus domestica Borkh. Phytochemistry 2009, 70, 348-360. [CrossRef] [PubMed]

36. Babula, D.; Misztal, L.H.; Jakubowicz, M.; Kaczmarek, M.; Nowak, W.; Sadowski, J. Genes involved in biosynthesis and signalisation of ethylene in Brassica oleracea and Arabidopsis thaliana: Identification and genome comparative mapping of specific gene homologues. Appl. Genet. 2006, 112, 410-420. [CrossRef] [PubMed]

37. Mekhedov, S.I.; Kende, H. Submergence enhances expression of a gene encoding 1-aminocyclopropane-1-carboxylate oxidase in deepwater rice. Plant Cell Physiol. 1996, 37, 531-537. [CrossRef]

38. Cheng, S.; Chen, P.; Su, Z.; Ma, L.; Hao, P.; Zhang, J.; Ma, Q.; Liu, G.; Liu, J.; Wang, H.; et al. High-resolution temporal dynamic transcriptome landscape reveals a GhCAL-mediated flowering regulatory pathway in cotton (Gossypium hirsutum L.). Plant Biotechnol. J. 2021, 19, 153-166. [CrossRef]

39. Schatlowski, N.; Kohler, C. Tearing down barriers: Understanding the molecular mechanisms of interploidy hybridizations. J. Exp. Bot. 2012, 63, 6059-6067. [CrossRef]

40. Chao, D.Y.; Dilkes, B.; Luo, H.; Douglas, A.; Yakubova, E.; Lahner, B.; Salt, D.E. Polyploids exhibit higher potassium uptake and salinity tolerance in Arabidopsis. Science 2013, 341, 658-659. [CrossRef] 
41. Ruiz, M.; Quinones, A.; Martinez-Cuenca, M.R.; Aleza, P.; Morillon, R.; Navarro, L.; Primo-Millo, E.; Martinez-Alcantara, B. Tetraploidy enhances the ability to exclude chloride from leaves in carrizo citrange seedlings. J. Plant Physiol. 2016, $205,1-10$. [CrossRef]

42. Yuan, H.; Yue, P.; Bu, H.; Han, D.; Wang, A. Genome-wide analysis of ACO and ACS genes in pear (Pyrus ussuriensis). Vitr. Cell Dev. Biol.-Anim. 2020, 56, 193-199. [CrossRef]

43. Abou-Rawash, M.; Abou-El-Nasr, N.; El-Masry, H.; Ebeed, S. Effect of spraying some chemical substances on flowering, fruit set, fruit drop, yield and fruit quality of Taimour mango trees. Egypt. J. Hortic. 1998, 25, 83-99.

44. Wertheim, S.; Estabrooks, E. Effect of repeated sprays of 6-benzyladenine on the formation of sylleptic shoots in apple in the fruit-tree nursery. Sci. Hortic. 1994, 60, 31-39. [CrossRef]

45. Rojas, W.; Solidum, P. Effects of different Ethrel concentrations on the flowering and fruit setting of pineapple (Ananas comosus L.). CMU J. Sci. 1990, 3, 25-32.

46. Williams, K. Each bloom delay using fall applications of ethrel and pro-gibb. Acta Hortic. 1989, 254, 151-154. [CrossRef]

47. Cheng, Y.; Yang, J.; Xu, F.; An, L.; Liu, J.; Chen, Z. Effects of ethylene promoter and inhibitor on morphology of flower organ and expressions of acc synthase gene in soybean (Glycine max L. Merr). J. Biotechol. 2008, 136, S226.

48. Jamil, M.; Lee, K.B.; Jung, K.Y.; Lee, D.B.; Han, M.S.; Rha, E.S. Salt stress inhibits germination and early seedling growth in cabbage (Brassica oleracea capitata L.). Pak. J. Biol. Sci. 2007, 10, 910-914. [CrossRef]

49. El-Maarouf-Bouteau, H.; Sajjad, Y.; Bazin, J.; Langlade, N.; Cristescu, S.M.; Balzergue, S.; Baudouin, E.; Bailly, C. Reactive oxygen species, abscisic acid and ethylene interact to regulate sunflower seed germination. Plant Cell Environ. 2015, 38, 364-374. [CrossRef]

50. Linkies, A.; Muller, K.; Morris, K.; Tureckova, V.; Wenk, M.; Cadman, C.S.; Corbineau, F.; Strnad, M.; Lynn, J.R.; Finch-Savage, W.E.; et al. Ethylene interacts with abscisic acid to regulate endosperm rupture during germination: A comparative approach using Lepidium sativum and Arabidopsis thaliana. Plant Cell. 2009, 21, 3803-3822. [CrossRef]

51. Silva, N.; de Souza, G.A.; Pimenta, T.M.; Brito, F.; Picoli, E.; Zsogon, A.; Ribeiro, D.M. Salt stress inhibits germination of Stylosanthes humilis seeds through abscisic acid accumulation and associated changes in ethylene production. Plant Physiol. Biochem. 2018, 130, 399-407. [CrossRef]

52. Yu, Y.; Wang, J.; Shi, H.; Gu, J.; Dong, J.; Deng, X.W.; Huang, R. Salt stress and ethylene antagonistically regulate nucleocytoplasmic partitioning of COP1 to control seed germination. Plant Physiol. 2016, 170, 2340-2350. [CrossRef]

53. Strader, L.C.; Chen, G.L.; Bartel, B. Ethylene directs auxin to control root cell expansion. Plant J. 2010, 64, 874-884. [CrossRef]

54. Ivanchenko, M.G.; Muday, G.K.; Dubrovsky, J.G. Ethylene-auxin interactions regulate lateral root initiation and emergence in Arabidopsis thaliana. Plant J. 2008, 55, 335-347. [CrossRef]

55. Feng, Y.; Xu, P.; Li, B.; Li, P.; Wen, X.; An, F.; Gong, Y.; Xin, Y.; Zhu, Z.; Wang, Y.; et al. Ethylene promotes root hair growth through coordinated EIN3/EIL1 and RHD6/RSL1 activity in Arabidopsis. Proc. Natl. Acad. Sci. USA 2017, 114, 13834-13839. [CrossRef]

56. Huang, G.T.; Ma, S.L.; Bai, L.P.; Zhang, L.; Ma, H.; Jia, P.; Liu, J.; Zhong, M.; Guo, Z.F. Signal transduction during cold, salt, and drought stresses in plants. Mol. Biol Rep. 2012, 39, 969-987. [CrossRef]

57. Achard, P.; Cheng, H.; De Grauwe, L.; Decat, J.; Schoutteten, H.; Moritz, T.; Van Der Straeten, D.; Peng, J.; Harberd, N.P. Integration of plant responses to environmentally activated phytohormonal signals. Science 2006, 311, 91-94. [CrossRef] [PubMed]

58. Peng, Z.; He, S.; Gong, W.; Sun, J.; Pan, Z.; Xu, F.; Lu, Y.; Du, X. Comprehensive analysis of differentially expressed genes and transcriptional regulation induced by salt stress in two contrasting cotton genotypes. BMC Genom. 2014, 15, 760. [CrossRef] [PubMed]

59. Yu, J.; Jung, S.; Cheng, C.H.; Ficklin, S.P.; Lee, T.; Zheng, P.; Jones, D.; Percy, R.G.; Main, D. CottonGen: A genomics, genetics and breeding database for cotton research. Nucleic Acids Res. 2014, 42, D1229-D1236. [CrossRef] [PubMed]

60. El-Gebali, S.; Mistry, J.; Bateman, A.; Eddy, S.R.; Luciani, A.; Potter, S.C.; Qureshi, M.; Richardson, L.J.; Salazar, G.A.; Smart, A.; et al. The Pfam protein families database in 2019. Nucleic Acids Res. 2019, 47, D427-D432. [CrossRef]

61. Ronquist, F.; Huelsenbeck, J.P. MrBayes 3: Bayesian phylogenetic inference under mixed models. Bioinformatics 2003, 19, 1572-1574. [CrossRef] [PubMed]

62. Artimo, P.; Jonnalagedda, M.; Arnold, K.; Baratin, D.; Csardi, G.; de Castro, E.; Duvaud, S.; Flegel, V.; Fortier, A.; Gasteiger, E.; et al. ExPASy: SIB bioinformatics resource portal. Nucleic Acids Res. 2012, 40, W597-W603. [CrossRef]

63. Letunic, I.; Bork, P. Interactive Tree Of Life (iTOL) v4: Recent updates and new developments. Nucleic Acids Res. 2019, 47, W256-W259. [CrossRef] [PubMed]

64. Bailey, T.L.; Johnson, J.; Grant, C.E.; Noble, W.S. The MEME Suite. Nucleic Acids Res. 2015, 43, W39-W49. [CrossRef] [PubMed]

65. Wang, Y.; Tang, H.; Debarry, J.D.; Tan, X.; Li, J.; Wang, X.; Lee, T.H.; Jin, H.; Marler, B.; Guo, H.; et al. MCScanX: A toolkit for detection and evolutionary analysis of gene synteny and collinearity. Nucleic Acids Res. 2012, 40, e49. [CrossRef] [PubMed]

66. Qiao, X.; Li, Q.; Yin, H.; Qi, K.; Li, L.; Wang, R.; Zhang, S.; Paterson, A.H. Gene duplication and evolution in recurring polyploidization-diploidization cycles in plants. Genome. Biol. 2019, 20, 38. [CrossRef] [PubMed]

67. Katoh, K.; Standley, D.M. MAFFT multiple sequence alignment software version 7: Improvements in performance and usability. Mol. Biol Evol. 2013, 30, 772-780. [CrossRef]

68. Zhang, Z.; Xiao, J.; Wu, J.; Zhang, H.; Liu, G.; Wang, X.; Dai, L. ParaAT: A parallel tool for constructing multiple protein-coding DNA alignments. Biochem. Biophys. Res. Commun. 2012, 419, 779-781. [CrossRef] [PubMed] 
69. Wang, D.; Zhang, Y.; Zhang, Z.; Zhu, J.; Yu, J. KaKs_Calculator 2.0: A toolkit incorporating gamma-series methods and sliding window strategies. Genom. Proteom. Bioinform. 2010, 8, 77-80. [CrossRef]

70. Nei, M.; Gojobori, T. Simple methods for estimating the numbers of synonymous and nonsynonymous nucleotide substitutions. Mol. Biol. Evol. 1986, 3, 418-426.

71. Pertea, M.; Kim, D.; Pertea, G.M.; Leek, J.T.; Salzberg, S.L. Transcript-level expression analysis of RNA-seq experiments with HISAT, StringTie and Ballgown. Nat. Protoc. 2016, 11, 1650-1667. [CrossRef]

72. Langfelder, P.; Horvath, S. WGCNA: An R package for weighted correlation network analysis. BMC Bioinform. 2008, 9, 559. [CrossRef]

73. Zhang, X.; Henriques, R.; Lin, S.S.; Niu, Q.W.; Chua, N.H. Agrobacterium-mediated transformation of Arabidopsis thaliana using the floral dip method. Nat. Protoc. 2006, 1, 641-646. [CrossRef]

74. Gu, L.; Wei, H.; Wang, H.; Su, J.; Yu, S. Characterization and functional analysis of GhWRKY42, a group IId WRKY gene, in upland cotton (Gossypium hirsutum L.). BMC Genet. 2018, 19, 48. [CrossRef]

75. Livak, K.J.; Schmittgen, T.D. Analysis of relative gene expression data using real-time quantitative PCR and the 2(-Delta Delta C(T)) Method. Methods 2001, 25, 402-408. [CrossRef] 